K.J. Robinson

6 Fife, KY16 8LB, UK.

$7 \quad{ }^{2}$ Scottish Oceans Institute, University of St Andrews, Scotland, KY16 8LB, UK.

$8 \quad{ }^{3}$ Department of Biosciences, Durham University, South Road, Durham, DH1 3LE, UK

$9 \quad *$ Corresponding author: Kelly J. Robinson, email: kjr33@st-andrews.ac.uk, phone: 01334462635 


\section{K.J. Robinson}

\section{Abstract}

22 Maximising infant survival requires secure attachments and appropriate behaviours between

23 parents and offspring. Oxytocin is vital for parent-offspring bonding and behaviour. It also

24 modulates energetic balance and neural pathways regulating feeding. However, to date the

25 connections between these two areas of the hormone's functionality are poorly defined. We

26 demonstrate that grey seal (Halichoerus grypus) mothers with high oxytocin levels produce pups

27 with high oxytocin levels throughout lactation, and show for the first time a link between

28 endogenous infant oxytocin levels and rates of mass gain prior to weaning. High oxytocin infants

29 gained mass at a greater rate without additional energetic cost to their mothers. Increased mass

30 gain in infants was not due to increased nursing, and there was no link between maternal mass

31 loss rates and plasma oxytocin concentrations. Increased mass gain rates within high oxytocin

32 infants may be due to changes in individual behaviour and energy expenditure or oxytocin

33 impacting on tissue formation. Infancy is a crucial time for growth and development, and our

34 findings connect the oxytocin driven mechanisms for parent-infant bonding with the energetics

35 underlying parental care. Our study demonstrates that oxytocin release may connect optimal

36 parental or social environments with direct physiological advantages for individual development.

\section{Keywords}

39 Maternal bonding; infant bonding; infant development; positive feedback loop; mass gain;

40 parental investment

\section{1. Introduction}

43 Parental attachment and care giving behaviours are of fundamental importance to reproductive

44 success in many species. Throughout the mammalian clade, maternal bonding and nurturing 


\section{K.J. Robinson}

45 behaviours are of particular importance, and infant survival is frequently solely dependent on how

46 mothers interact with their offspring. Mothers cannot succeed in raising offspring without some

47 degree of co-ordination between parties to accomplish the common goal of infant survival to

48 independence (Fleming et al., 1999). Cognitive and physiological systems that promote

49 behavioural synchrony across parent-infant dyads play a vital role in this co-ordination. However,

50 any mechanism that enables parent-infant interactions must function despite changing infant

51 cognitive abilities as they develop across the period they are dependent on their parent(s) (Rice

52 and Barone, 2000). Therefore, in infants, physiological systems mediating behavioural expression

53 may be key to keeping dependent offspring with their parents and ensuring infants act

54 appropriately towards them and other conspecifics.

56 The neuropeptide hormone oxytocin (OT) is vital for both social and parental bonding, plays a

57 key role in the initiation of maternal behaviour and in some species mediates the continuance of

58 good quality infant care throughout the dependent period (Gimpl and Fahrenholz, 2001; Ross and

59 Young, 2009; Rilling and Young, 2014). At birth, a mother's OT release initiates bonding with

60 her infant and maternal care (Gimpl and Fahrenholz, 2001; Ross and Young, 2009). It has been

61 theorised that OT then acts in a positive feedback loop within mother-infant pairs to develop

62 secure attachment between the two and to mediate maternal behaviour directed towards the infant

63 (Rilling and Young, 2014; Nagasawa et al., 2012). A mother's OT feedback loop is initiated via

64 filial infant stimuli causing additional OT release in the mother after birth (Strathearn et al.,

65 2009). This OT expression has been shown to trigger care giving behaviours towards human

66 infants while activating dopamine 'reward' systems a mother's brain (Strathearn et al., 2009), and

67 in humans there is high co-expression between OT and dopaminergic receptor genes to facilitate

68 this (Quintana et al., 2019). Then, by performing care giving behaviours towards her infant, a

69 mother is more likely to be exposed to additional infant stimuli that causes even more OT release 


\section{K.J. Robinson}

70 in the mother, perpetuating the 'loop' and generating elevated OT concentrations within securely

71 attached mothers (Rilling and Young, 2014). This positive feedback loop is also theorised to exist

72 in the infant, with good quality maternal care causing infant attachment to the mother and OT

73 release due to parental stimuli (Kojima et al., 2012), generating high OT concentrations in the

74 infant. Therefore, if double positive OT feedback loops exist in mother-infant pairs, with one loop

75 in each individual, high OT mothers should also have high OT infants (Rilling and Young, 2014).

76 Experiments using non-filial socially bonded individuals show that positive OT feedback loops

77 exist across individuals in social contexts (Nagasawa et al., 2015). However, there is no evidence

78 to date that such loops exist within mother-infant pairs, due to a lack of data on infant OT

79 responses alongside their mother's OT concentrations.

81 While the effects of changing OT concentrations within mothers is well studied (Gimpl and

82 Fahrenholz, 2001), impacts on infants, or the physiology of peripheral tissues, remain poorly

83 understood. There is evidence from laboratory manipulation studies that OT influences the

84 development of a variety of peripheral tissues (Uvnäs-Moberg et al. 1998; Elabd et al., 2014;

85 Colaianni et al., 2015; Rault et al., 2015) and exposure to OT during infancy can have long term

86 impacts on weight gain (Uvnäs-Moberg et al. 1998), as this time period is crucial for body growth

87 and formation (Metcalfe and Monaghan, 2001). In humans (Homo sapiens) problems with infant

88 nutrition and development are estimated to cause $45 \%$ of deaths in children under five years old

89 globally, with suboptimal breastfeeding, growth stunting and wasting critically affecting child

90 development and survival in the first 1000 days of life (Black et al. 2013). Current interventions

91 to overcome infant 'failure to thrive' in humans, such as complimentary feeding, only show

92 modest success in tackling these problems (Dewey and Adu-Afarwuah, 2008) and understanding

93 physiological mechanisms driving an infant's ability to gain weight and mature is therefore of

94 great importance. If the mass changes induced via OT manipulations in laboratory settings can be 


\section{K.J. Robinson}

95 detected in natural systems, then elevation of infant OT through successful bonding and

96 interacting with maternal figures would be a fundamental driver of an infant's ability to thrive and

97 reach independence.

98

99 Grey seals (Halichoerus grypus) are colonially breeding marine mammals, with females that

100 produce one pup per year. The pups are nursed on high fat milk while mothers fast before

101 weaning abruptly approximately 18 days post-partum (Pomeroy et al., 1999). They present an

102 excellent model system to study maternal behaviour and physiology as blood samples can be

103 collected from both adults and infants, mothers are solely responsible for raising pups to

104 independence, are individually identifiable and the entire dependent period can be observed in a

105 relatively short time period for a large mammal. Additionally, of the few OT systems studied in

106 animal species in the wild, to date the most is known about grey seals (Robinson et al., 2014;

$1072015 ; 2017)$. In this study mother-pup pairs were monitored to assess whether mothers with high

108 OT concentrations produced pups with high OT concentrations, and whether the variation in OT

109 concentrations within mothers and pups were correlated to patterns of mass change across the

110 dependent period.

\section{2. Materials and Methods}

\subsection{Study sites and animals}

114 Field work was conducted on the island of North Rona (NR), Scotland (59॰06`N, $\left.05^{\circ} 50^{`} \mathrm{~W}\right)$ and

115 the Isle of May (IoM), Scotland $\left(56^{\circ} 11^{\prime} \mathrm{N}, 02^{\circ} 33^{\prime} \mathrm{W}\right)$, both grey seal breeding colonies with long

116 term research projects. Data and samples were collected from both colonies during the winter

117 breeding season in 2010 and 2011. Across the two study years, plasma samples were collected

118 from 66 mothers and their pups (36 from NR, 30 from the IoM). 20 mothers occurred in both 


\section{K.J. Robinson}

119 study years (11 from NR, 9 from the IoM). Mothers were identified by unique markings (natural

120 pelage patterns, or applied tags or brands (Smout et al., 2011)). Sampling was restricted to

121 mothers first seen either pre-partum or with newborn pups. We attempted to capture mother-pup

122 pairs twice during the lactation period to obtain plasma samples at 1-7 days after the pup's birth

123 ('early lactation') then 9-15 days after the first sampling event ('late lactation') (Robinson et al.,

124 2015a). We also attempted to re-capture as many pups post-weaning as possible during the

125 natural 1-4 week post-weaning fast in this species (Reilly 1991), and sampled 43 weaned study

126 pups (15 from NR, 28 from the IoM).

\section{2.2 Mass Measurements, Plasma and Milk Sampling and Analysis}

129 Grey seal mothers with pups were approached, captured, weighed and sampled as previously

130 described (Pomeroy et al., 1999; Robinson et al., 2015a). The use of chemical immobilization

131 ameliorates physiological stress responses to capture and handling in phocid seals (Harcourt et al.,

132 2010), and prior validation studies have shown that in grey seals, there was no change in plasma

133 OT with handling time (Robinson et al., 2014; 2015b) and no difference in extracted plasma OT

134 levels across chemically immobilized or physically restrained seals (Robinson et al. 2014).

135 Plasma samples were collected by venipucture, transported to a field laboratory and stored frozen

136 at $-20^{\circ} \mathrm{C}$ as described in Robinson et al. (2014; 2015). Our capture protocol meant that there was

137 always a 10-minute wait for mothers to become immobilised before a plasma sample could be

138 collected. This wait would eliminate any plasma OT peaks triggered by pre-capture nursing as OT

139 has a short half-life in plasma (Robinson et al., 2014). It is typically only possible to obtain milk

140 samples from seal mothers after an intravenous OT injection, however this could have

141 confounded endogenous OT concentrations in the milk collected. Using plastic $20 \mathrm{ml}$ syringes

142 adapted for drawing milk, two milk samples were successfully collected from grey seal mothers

143 without the use of exogenous OT. The analysis protocol for milk samples supplied with the OT 


\section{K.J. Robinson}

144 ELISA (see above) was followed with two alterations, detailed in the supplementary materials

145 (Appendix A. Methods), to prevent the high fat content of the milk (60\%, (Iverson et al., 1993))

146 interfering with the assay.

147

148 Plasma was analysed for OT in duplicate using an ELISA (produced by Assay Designs Inc. at the

149 time of this analysis, ELISA kit is currently produced by Enzo Life Sciences but uses a different

150 antibody) with each sample undergoing solid-phase extraction prior to analysis following

151 methodology previously validated for detecting phocid plasma OT (Robinson et al., 2014). Plates

152 were read using a BioTek ELx800 reader. The standard curve and assay results for all plates were

153 fitted using the calibFit package (Haaland et al., 2011) in R version 2.15.0 (R Development Core

154 Team, 2012). Recovery rates for the extraction and ELISA procedure were $107.2 \%(\mathrm{n}=10)$, inter-

155 assay coefficient of variance (COV) over the 14 plates used in this study was $16.1 \%$ and intra-

156 assay COV for this assay was 3.5\%.

\subsection{Statistical Analysis}

159 All analyses were performed using the statistical package R 3.4.1 (R Development Core Team, 160 2012).

162 Plasma concentrations for mothers and their pups in early and late lactation were compared using

163 a one-way ANOVA. The data were analysed after a natural log transformation as the original data

164 were not normally distributed (Shapiro Wilk test, $\mathrm{p}<0.001$ ). Basal plasma OT concentrations were

165 also calculated for the 43 post-weaning pups that we were able to locate on the colony. The OT

166 concentrations from these individuals during early lactation (with mother), late lactation (with

167 mother) and post-weaning (without mother) were compared using a one-way ANOVA. The data 


\section{K.J. Robinson}

168 were analysed after a natural $\log$ transformation as the original data were not normally distributed

169 (Shapiro Wilk test, $\mathrm{p}<0.001$ ).

171 GAMMs (Wood, 2006) were used to analyse variables affecting the OT concentration detected in

172 dependent pups and for exploring the relationships between variables affecting mass gain in pups

173 and mass loss in mothers. Details of model construction, selection process and the final model

174 coding are given in the supplementary materials (Appendix A. Methods), For the GAMMs

175 investigating pup mass gain and mother mass loss, rates of mass change were calculated in $\mathrm{kg} /$ day

176 for all mother-pup pairs which had mass measurements and were sampled for plasma OT

177 detection in both early and late lactation $(n=58$ mother-pup pairs). Larger grey seal mothers lose

178 mass at a faster rate than smaller mothers (Iverson et al., 1993); therefore, the rate of mass loss

179 (kg/day) for all mothers was transformed by dividing mass loss rates by the mother's mass at first

180 capture, during early lactation. This gave individual mass specific rates of mass loss for all

181 mothers for use in subsequent analysis. In pups, plasma OT concentrations detected in early and

182 late lactation were significantly positively correlated $(\mathrm{r}=0.54, \mathrm{p}<0.001,95 \%$ CIs [0.32, 0.7],

183 Appendix A. Methods, Figure A.1) and therefore a mean of the two values was used to correlate

184 with mass gain. Mother plasma OT concentrations across the early and late sampling points were

185 not significantly correlated $(\mathrm{r}=0.12, \mathrm{p}=0.37,95 \%$ CIs [-0.14, 0.37], Appendix A. Methods,

186 Figure A.2) and therefore concentrations from early and late lactation were analysed separately

187 with the transformed mass loss rate.

189 3. Results

\subsection{OT concentrations in mothers and pups}

191 Basal plasma OT concentrations in pup plasma were significantly higher than those detected in 192 mothers throughout early and late lactation (Figure 1, ANOVA: F3,232=141.4, p<0.001). No 


\section{K.J. Robinson}

193 significant differences were detected between pups in early and late lactation (mean \pm SE: 21.9

$194 \pm 1.5 \mathrm{pg} / \mathrm{ml}$ and $19.9 \pm 1.4 \mathrm{pg} / \mathrm{ml}$ respectively, Tukey honest significant difference test, $\mathrm{p}=0.5)$ or

195 mothers in early and late lactation (mean \pm SE: $8.2 \pm 0.6 \mathrm{pg} / \mathrm{ml}$ and $7.6 \pm 0.5 \mathrm{pg} / \mathrm{ml}$ respectively,

196 Tukey honest significant difference test, $\mathrm{p}=0.7)$. Maternal plasma OT concentrations ranged

197 from $3.5-25.5 \mathrm{pg} / \mathrm{ml}$ in early lactation and $3.5-16.9 \mathrm{pg} / \mathrm{ml}$ in late lactation. Pup plasma OT

198 concentrations ranged from $11.5-48.1 \mathrm{pg} / \mathrm{ml}$ in early lactation and $8-52.2 \mathrm{pg} / \mathrm{ml}$ in late

199 lactation. There was a significant positive relationship between pup plasma OT concentration and

200 that of its mother (Figure 2, GAMM: R2 $=0.34, \mathrm{p}=0.02$, Appendix B. Table B.1). Pups from NR

201 also had significantly higher plasma OT concentrations than pups from the IoM (Figure 2,

$202 \mathrm{p}<0.001)$.

\subsection{Maternal presence vs. milk OT as drivers of high infant OT}

205 To explore whether maternal presence may be driving elevated OT levels in pups, samples of 206 plasma OT from as many pups as possible were collected after weaning, when mothers were

207 absent during the natural 1-4 week post-wean fast that occurs in this species (Reilly, 1991). Pups

208 that had weaned from their mothers had significantly lower plasma OT concentrations (10.9

$209 \pm 0.9 \mathrm{pg} / \mathrm{ml}$ ) than when they were with their mothers in both early or late lactation (Figure 3,

210 ANOVA: $F 2,126=37.18, p<0.001$, Tukey honest significant difference test, $p=0.5$ between early

211 and late pup groups and $\mathrm{p}<0.001$ between weaned pups and all non-weaned pup groups).

213 To explore whether pups may be ingesting and absorbing OT from their mothers' milk, milk

214 samples were collected from as many grey seal mothers as possible $(\mathrm{n}=2)$ to estimate

215 concentrations of OT that pups ingest from milk consumption. The two milk samples collected

216 contained 128.9 and $95.6 \mathrm{pg} / \mathrm{ml} \mathrm{OT}$, giving a mean of $112.2 \pm 16.6 \mathrm{pg} / \mathrm{ml}$ (SE) in phocid milk. 


\section{K.J. Robinson}

219 Pup mass gain rate was linked to mean pup plasma OT concentrations across the lactation period

220 (GAMM: R2 $=0.38, p=0.016$, Appendix B. Table B.2) with the two being significantly

221 positively correlated $(\mathrm{r}=0.35, \mathrm{p}=0.007,95 \%$ CIs [0.1, 0.6], Figure 4). A mother's rate of mass

222 loss was independent of maternal OT concentrations in both early and late lactation (GAMM: R2 $223=0.31, \mathrm{p}=0.17$ and $\mathrm{p}=0.11$ respectively, Appendix B. Table B.3).

\section{Discussion}

\subsection{High OT mothers produce high OT pups}

227 The results for this study support the existence of positive OT feedback loops within mothers and 228 pups in both of the seal colonies studied. Maternal and pup plasma OT concentrations were

229 significantly higher on average than those detected in non-breeding female grey seals $(4.3 \pm 0.5$

$230 \mathrm{pg} / \mathrm{ml}$, Robinson et al., 2015a), but there was great variation in individual values, especially

231 within pups. Data on infant plasma OT levels are currently scarce, however, two studies

232 measuring newborn OT plasma levels exist for humans and laboratory mice that mirror the OT

233 patterns reported in this study. Human newborns had elevated plasma OT concentrations

234 compared to adults in a study monitoring them for the first 4 days of life (Leake et al., 1981),

235 while weaned human children have plasma OT concentrations comparable to those in adults

236 (children 6-11 years: 1.2pg/ml (Modahl et al., 1998), adults: $<2 \mathrm{pg} / \mathrm{ml}$ (Szeto et al., 2011).

237 Laboratory mice pups approaching and at the point of weaning also have high plasma OT levels 238 compared to other developmental stages (Higashida et al., 2010). Elevated OT levels are known

239 to trigger proximity seeking behaviours in adult and infant grey seals (Robinson et al., 2015a;

240 2017), If stimuli from the presence of the mother/pup is causing the high OT concentrations 


\section{K.J. Robinson}

241 recorded across the pair, the mother-infant positive feedback loop system proposed by Rilling and

242 Young (2014) can be constructed with our data from a natural population (Figure 5).

244 By documenting infant OT concentrations alongside their mother's levels, we provide the first 245 evidence, to our knowledge, of double OT loops in mother-infant pairs, with one loop in each

246 individual but dependent on each other's presence for their continuation (Figure 5). Such loops

247 would act to keep mothers and offspring together, synchronising them behaviourally and

248 physiologically towards the common goal of infant survival. The structure and function of OT is

249 widely conserved across the mammalian clade (Gimpl and Fahrenholz, 2001; Feldman et al.,

250 2016; Jurek and Neumann 2018). Thus far, grey seals have been shown to posses an OT system

251 that is directly comparable to other domestic or captive animal species and humans, as their basal

252 plasma concentrations, plasma clearance rates and maternal patterns of plasma OT expression

253 match those detected in laboratory model species and humans (Robinson et al., 2014; 2015).

254 Therefore, it is likely that the evidence for positive OT feedback loops across mother-infant pairs

255 from grey seals would be present in other species.

257 The relevance of peripheral OT concentrations compared to central OT concentrations, and

258 whether any meaningful correlations exist between the two is still debated (Valstad et al., 2017).

259 However, peripheral and central release of OT due to stimuli from dependent infants has been

260 documented in humans and rodents, including nursing, sounds and sight of the infant and

261 interacting with the infant (Strathearn et al., 2009; Uvnäs-Moberg et al., 1998). Peripheral OT

262 concentrations are also arguably more relevant to measure when investigating links between the

263 hormone's concentrations in relation to mass changes in peripheral tissues, such as adipose

264 deposits or skeletal muscle. 


\section{K.J. Robinson}

267 Our study found that pup plasma OT concentrations remain consistently high throughout the

268 dependent period, only decreasing once they weaned and the mother was no longer present. A

269 pup's developmental stage and the fasting state weaned pups enter as soon as the mother leaves

270 could theoretically influence plasma OT levels. However, OT concentrations in individual grey

271 seal pups show no variation across two weeks of fasting (Robinson et al., 2015b) and remain

272 consistent when pups leave the breeding colony and start feeding at approximately one month of

273 age, and throughout their first year of life $(8.3 \pm 0.6 \mathrm{pg} / \mathrm{ml}$, Robinson et al., 2014). There is also

274 no change in plasma OT levels across the various developmental stages either side of weaning, as

275 levels in newborns are comparable to pups approaching weaning (see results section 3.1), pups

276 that have been fasting for 3 days are comparable to those who have fasted for several weeks

277 (Robinson et al. 2015b) and fasting pups are comparable to all other developmental stages in the

278 first year of life (Robinson et al., 2014). Pup OT decreases significantly and consistently in the

279 first three days of the mother leaving, regardless of the age at time of weaning (Robinson 2014).

280 Pup plasma OT levels are subsequently stable for weeks despite undergoing sustained fasting and

281 substantial developmental changes, and do not change as pups shift from fasting to feeding or

282 undergo all the developmental changes that occur in their first year. It is more likely that some

283 aspect of maternal presence is driving elevated OT in dependent pups, because once the mother

284 leaves and this stimulus is removed, pup OT levels fall.

286 Ingestion of OT from breast milk has been proposed as a route of neonatal exposure to this

287 hormone in humans (Uvnäs-Moberg et al., 1998; Carter, 2003) and mice (Higashida et al., 2010).

288 Higashida et al. (2010) attribute ingested milk as the cause of high OT levels in mouse pups due 289 to the sheer quantity of OT present in mouse milk. However, this interpretation must be viewed 


\section{K.J. Robinson}

290 with caution, as the OT levels reported from that study indicate that unextracted substrates were

291 used in the analysis which gives high, inaccurate results (Robinson et al., 2014; Leng and

292 Sabatier, 2016). Higashida et al. (2010) also only detect the amount of OT in mouse milk, without

293 putting this value into context with how much mice pups actually drink. Other studies state that

294 physical barriers to absorption and uptake and chemical degradation in the digestive tract make

295 ingested milk an unlikely source of significant amounts of OT in infants (Fiellestad-Paulsen et al.,

296 1995). Even when medical trials have given high buccal doses of OT to humans, their ability to

297 raise plasma OT concentrations is limited (Dawood et al., 1980; Landgraf 1985). When put into

298 context with the OT we detected in seal milk and the volumes of milk a seal pup ingests daily, it

299 is apparent that the OT levels in seal milk are not high enough to impact on plasma concentrations

300 (see Appendix C and Table C.4 for these calculations). The low number of milk samples that

301 were obtained $(n=2)$ is a potential limitation of this study, as additional mothers may yield

302 samples with higher OT concentrations. However, even if the questionably high OT levels

303 detected in laboratory rat milk from Higashida et al. (2010) is used to calculate whether ingested

304 OT could impact on pup plasma levels, these milk concentrations are still far too low to raise

305 infant plasma levels significantly (see Appendix C and Table C.4 for these calculations). It is

306 therefore plausible that aspects of the mother's presence other than her ability to provide milk are

307 driving elevated OT in pups, potentially including the scent, sounds and sight of the mother.

309 Conspecific stimuli from individuals that are bonded to each other have already been shown to 310 cause elevations in peripheral OT (Strathearn et al., 2009, Nagasawa et al., 2015). Other findings

311 from this study also lend support to the theory that it is a mother's presence driving high pup OT

312 levels. The inter-colony differences in mother-pup OT levels show that NR mother-pup pairs had

313 significantly higher plasma OT than IoM pairs. Mothers on NR spend more time in close

314 proximity to their pups than mothers on IoM (Redman et al., 2002) primarily due to topographical 


\section{K.J. Robinson}

315 differences at the two colonies affecting access to water (Caudron et al., 2001; Redman et al.,

316 2002). According to the positive loop theory, more time in close proximity equates to greater OT

317 release and concentrations in bonded individuals, and the OT results from the two colonies agree

318 with this (Fig 2).

320 An endocrinological system that stimulates synchrony of both physiology and behaviour across

321 individuals has the potential to act on other important bonds outside of maternal ones. There is

322 evidence from social insects that complex social traits evolve from co-opting systems acting on

323 maternal behaviour and physiology (Amdam et al., 2006), and it seems likely this has happened

324 with the positive OT loop mechanism. There is already direct evidence that positive OT loops

325 stimulate pro-social behaviour and elevate OT concentrations across socially bonded, but

326 unrelated pairs even across species boundaries (Nagasawa et al., 2015). Therefore, this unique

327 mechanism could enable the co-ordination of a number of individuals' physiology, across pairs or

328 groups. By aligning group members' motivation to perform specific behaviours, OT may

329 stimulate group synchrony even when faced with individual risks such as serious injury or death

330 (Samuni et al., 2016). The existence of co-operative behaviour has generated much research into

331 theoretical reasons for its development and perpetuation in individuals, populations and species;

332 however, the underlying physiological mechanisms driving such behaviour remain relatively

333 poorly understood (Soares et al., 2010). The OT loop system acting both within individuals and

334 across group or bond members is a promising area for future work, uncovering how individuals

335 can be motivated to act against their own interests in high risk or low reward contexts. 


\section{K.J. Robinson}

340 High OT concentrations were associated with greater pup growth rates without extra energetic

341 cost to their mothers, as no differences in relative maternal mass loss rates were detected. Two

342 results suggest that the difference in mass gain rates between high and low OT pups is not due to

343 variation in how much milk pups ingest. First, behavioural data was collected from the NR

344 mother-pup pairs in this study, and their plasma OT concentrations showed no relationship with

345 variation in nursing bout frequency or duration (Robinson et al., 2015a). Second, if high OT pups

346 were achieving their additional mass gain by ingesting more milk from their mothers, those

347 mothers would show greater mass loss rates per day than low OT mothers, which was not

348 observed. OT is known to modulate feeding in mammalian species (Gaetani et al., 2010; Atasov

349 et al., 2012) and has been shown to reduce food intake in several animal species (reviewed in

350 Olszewski et al., 2010). This may explain why infants with elevated OT concentrations are not

351 motivated to nurse more from their mothers. However, it does not explain how high OT infants

352 are able to gain mass at a higher rate, without ingesting additional milk.

354 The variation in mass gain across high to low OT pups may be due to behavioural differences

355 impacting individual metabolism and fat accumulation in pups. The elevated OT concentrations

356 in pups are likely indicative of successful mother-pup attachment, and elevated OT would trigger

357 pups to remain close to their mothers (Robinson et al., 2015a; 2017). This may reduce energetic

358 expenditure in pups by preventing excursions away from their mother, which would elevate

359 metabolic rate and initiate conflicts with adjacent seals. It is also possible that by encouraging

360 pups to remain close to their mothers, high OT pups are more sheltered from strong winds

361 (McCafferty et al., 2005), experiencing a microclimate that reduces their thermal output and

362 lowers metabolic overheads. OT manipulations in laboratory rats indicate that the hormone

363 triggers huddling behaviour (Alberts 2007) and modulates the function of brown adipose tissue, 


\section{K.J. Robinson}

364 directly impacting on thermoregulation in infants (Harshaw et al., 2018). Therefore, rather than

365 actively stimulating mass gain, elevated OT concentrations in pups may reduce activities that

366 divert resources away from growth prior to weaning.

368 With the growing body of evidence linking OT to the development of several tissue types, it is

369 also possible that elevated OT in pups stimulates physiological pathways that cause increased

370 mass development. Experiments giving OT to rat pups promoted weight gain in adults via

371 increased deposition of adipose tissue (Uvnäs-Moberg et al., 1998) and when given to young pigs

372 (Sus scrofa domesticus), OT reduced mass lost during weaning events (Rault et al., 2015). OT has

373 also been linked to skeletal muscle development in mice (Mus musculus) (Elabd et al., 2014) and

374 bone mass accumulation in mice and humans (Colaianni et al., 2015). Physiological pathways for

375 increased OT concentrations influencing mass changes independent of food intake have been

376 proposed (Rault et al., 2015; Colaianni et al., 2015), such as OT causing the stimulation of

377 digestive activity and fat storage by linking increases in plasma cholecystokinin, insulin and

378 adipose tissue in OT treated rats (Uvnäs-Moberg et al., 1998). More research is needed to identify

379 which biological tissues are affected by OT, so that the developmental consequences for exposure

380 to high or low OT levels due to variation in social or parental stimuli can be determined.

382 Grey seal mothers fast while nursing their pups and lose up to $40 \%$ of their body mass at 383 parturition during this time (Pomeroy et al., 1999), using approximately $80 \%$ of their energetic 384 reserves to produce milk and sustain themselves on the colony (Fedak and Anderson, 1982). The 385 ability to wean at as large a mass as possible is the most important factor affecting grey seal pup 386 survival in its first year of life (Hall et al., 2001). That OT facilitates mass gain or slows mass loss 387 in dependent pups with no additional energetic cost to the mother is of great importance in a true 388 capital breeding species which has rapid offspring mass gain and abrupt termination of maternal 


\section{K.J. Robinson}

care. Any physiological factors enabling efficient mass gain in infants will be highly selected for

390 as it would increases the probability of success for a mother within that breeding episode without

391 additional investment costs.

393 Steady mass gain postpartum is crucial for successful infant development and survival in all

394 animal species, including humans (Black et al., 2013; Shields et al., 2012). Any factors that

395 increase infant mass gain while minimising the energetic costs to parents is highly advantageous

396 in any species exhibiting parental care. All organisms must give their offspring the best

397 developmental start in life while attempting to balance the negative costs to themselves; any

398 factor reducing the conflict between these two contrasting demands on an organism will impact

399 on their survival, their current and future reproductive success. A link between good maternal

400 care, high OT and increased infant mass gain has been previously proposed in rodents based on

401 manipulating OT levels experimentally (Uvnäs-Moberg et al., 1998). Additionally, a study

402 investigating weight gain and massage therapy in preterm human babies theorised that elevated

403 plasma OT in babies receiving massages indicated a role for the hormone in mediating infant

404 weight gain (Field, 2001). To our knowledge, our study provides the first evidence of an OT-mass

405 gain relationship in wild mother-infant pairs and highlights the importance of understanding the

406 hormone's role in mediating mother-infant bonds, care giving behaviour and physical

407 development in infants.

\section{5. Conclusions}

410 Our study provides the first evidence that positive OT loops acting across bonded individuals

411 exist in mother-infant pairs in natural environments, and that they are linked to the promotion of

412 infant development without additional energetic costs to mothers. Including energetic benefits in 


\section{K.J. Robinson}

413 the proposed loop mechanism highlights how such systems physiologically give selective

414 advantage to securely bonded mother-infant pairs (Figure 5). OT facilitates and regulates parental

415 and social bonds throughout the mammalian clade, with OT-like peptides in bird

416 (Chokchaloemwong et al., 2013) and fish (O'Connell et al., 2012) species fulfilling similar roles

417 in other vertebrate groups. OT loops and the associated fitness benefits linked to them may

418 therefore be a widespread mechanism for connecting optimal parental or social environments

419 with direct physiological advantages for individual development. Understanding the mechanisms

420 by which OT and OT-like peptides affect interactions between the bonded individuals and infant

421 mass gain has wide ranging implications for animal husbandry practises, medical interventions,

422 advice to human parents, societal understanding of how health and relationships are linked and

423 studying the energetic constraints of parental care.

\section{Acknowledgements}

426 We would like to thank William Patterson, Hannah Wood, Simon Moss, Matthew Bivins, Paula

427 Redman, Theoni Photopoulou, Johanna Baily and everyone who assisted with the sample

428 collection on North Rona and the Isle of May during the 2010 and 2011 seasons. The help and

429 cooperation of Scottish National Heritage, HM Coastguard and the Northern Lighthouse Board

430 are gratefully acknowledged.

\section{$432 \quad$ Funding}

433 The UK's Natural Environmental Research Council (NERC) funded the long-term program of 434 research on grey seals at North Rona and the Isle of May. PPP and SDT were in receipt of NERC 435 grant NE/G008930/1 and PPP was in receipt of Esmée Fairburn Foundation grant 08-1037 during 436 the work. This paper formed part of KJR's PhD funded by the UK Natural Environment Research 


\section{K.J. Robinson}

437 Council (NERC) grant NE/H524930/1 and by SMRU Marine, St Andrews, UK. The funding

438 bodies had no role in the design of the study, the collection of samples, the analysis of samples or

439 data and the interpretation of the data.

\section{$441 \quad$ Ethical approval}

442 All animal procedures were performed under the UK Home Office project license \#60/4009 and

443 conformed to the UK Animals (Scientific Procedures) Act, 1986. All research received prior

444 ethical approval from the University of St Andrews Animal Welfare and Ethics Committee and

445 the School of Biology's Ethics Committee.

447 Data Availability

448 The dataset supporting the conclusions of this article is included within the article and its

449 Appendices (Appendix D).

451 Competing interests

452 Declarations of interest: none

\section{Authors' contributions}

455 KJR conceived the study; KJR, SDT and PPP collected samples in the field; KJR performed all 456 sample and data analysis; NH provided essential laboratory equipment; KJR wrote the 457 manuscript; all authors critically revised the manuscript and gave final approval of the version to 458 be published. 


\section{K.J. Robinson}

\section{References}

461 1. Alberts JR. 2007 Huddling by rat pups: ontogeny of individual and group behavior. Dev. Psychobiol. 49, 22-32.

2. Amdam GV, Csondes A, Fondrk, MK, Page RE. 2006 Complex social behaviour derived from maternal reproductive traits. Nature 439, 76-78.

3. Atasoy D, Betley JN, Su HH, Sternson SM. 2012 Deconstruction of a neural circuit for hunger. Nature 488, 172.

4. Black RE, Victora CG, Walker SP, Bhutta ZA, Christian P, De Onis M, Ezzati M, Grantham-McGregor S, Katz J, Martorell R, Uauy R. 2013 Maternal and child undernutrition and overweight in low-income and middle-income countries. Lancet 382, 427-451.

5. Carter CS. 2003 Developmental consequences of oxytocin. Physiol. Behav. 79, 383-397.

6. Caudron AK, Joiris CR, Ruwet JC. 2001 Comparative activity budget among grey seal (Halichoerus grypus) breeding colonies-the importance of marginal populations. Mammalia; 65, 373-382.

7. Chokchaloemwong D, Prakobsaeng N, Sartsoongnoen N, Kosonsiriluk S, El Halawani M, Chaiseha Y. 2013 Mesotocin and maternal care of chicks in native Thai hens (Gallus domesticus). Horm. Behav. 64, 53-69.

8. Colaianni G, Sun L, Zaidi M, Zallone A. 2015 The "love hormone" oxytocin regulates the loss and gain of the fat-bone relationship. Front. Endocrinol. 6, 79. after buccal Pitocin. Am. J. Obstet. Gynecol. 138, 20-24.

10. Dewey KG, Adu-Afarwuah S. 2008 Systematic review of the efficacy and effectiveness of complementary feeding interventions in developing countries. Matern. Child Nutr. 4, 24-85. 


\section{K.J. Robinson}

11. Elabd C, Cousin W, Upadhyayula P, Chen RY, Chooljian MS, Li J, Kung S, Jiang KP, Conboy IM. 2014 Oxytocin is an age-specific circulating hormone that is necessary for muscle maintenance and regeneration. Nat. Commun. 5, 4082.

12. Fedak MA, Anderson SS. 1982 The energetics of lactation: accurate measurements from a large wild mammal, the grey seal (Halichoerus grypus). J. Zool. 198, 473-479.

13. Feldman R, Monakhov M, Pratt M, Ebstein RP. 2016 Oxytocin pathway genes: evolutionary ancient system impacting on human affiliation, sociality, and psychopathology. Biol. Psychiat. 79, 174-184.

14. Field T. 2001 Massage therapy facilitates weight gain in preterm infants. Curr. Dir.

16. Fleming AS, O’Day DH, Kraemer GW. 1999 Neurobiology of mother-infant interactions: experience and central nervous system plasticity across development and generations. Neurosci. Biobehav. R. 23, 673-685. Giannini E, Scaccianoce S, Mairesse J. 2010 The fat-induced satiety factor oleoylethanolamide suppresses feeding through central release of oxytocin. J. Neurosci. 30, 8096-8101.

18. Gimpl G, Fahrenholz F. 2001 The oxytocin receptor system: structure, function, and regulation. Physiol. Rev. 81, 629-683.

19. Haaland P, Samarov D, McVey E. 2011 calibFit: Statistical models and tools for assay calibration. R package version 2.1.0/r17. Available from: http://R-Forge.Rproject.org/projects/calibfun/ 


\section{K.J. Robinson}

510

511

512

513

514

515

516

517

518

519

520

521

522

523

524

525

526

527

528

529

530

531

532

533

20. Hall AJ, McConnell BJ, Barker RJ. 2001 Factors affecting first - year survival in grey seals and their implications for life history strategy. J. Anim. Ecol. 70, 138-149.

21. Harcourt RG, Turner E, Hall A, Waas JR, Hindell M. 2010 Effects of capture stress on free-ranging, reproductively active male Weddell seals. J. Comp. Physiol. A. 196, 147154.

22. Harshaw C, Leffel JK, Alberts JR. 2018. Oxytocin and the warm outer glow: Thermoregulatory deficits cause huddling abnormalities in oxytocin-deficient mouse pups. Horm. Behav 98, 145-158.

23. Higashida H, Lopatina O, Yoshihara T, Pichugina YA, Soumarokov AA, Munesue T, Minabe Y, Kikuchi M, Ono Y, Korshunova N, Salmina, AB. 2010 Oxytocin signal and social behaviour: comparison among adult and infant oxytocin, oxytocin receptor and CD38 gene knockout mice. J. Neuroendocrinol. 22, 373-379.

24. Iverson SJ, Bowen WD, Boness DJ, Oftedal OT. 1993 The effect of maternal size and milk energy output on pup growth in grey seals (Halichoerus grypus). Physiol. Zool. 66, $61-88$.

25. Jurek B, Neumann ID. 2018 The oxytocin receptor: from intracellular signaling to behavior. Physiol. Rev. 98, 1805-1908.

26. Kojima S, Stewart RA, Demas GE, Alberts JR. 2012 Maternal contact differentially modulates central and peripheral oxytocin in rat pups during a brief regime of motherpup interaction that induces a filial huddling preference. J. Neuroendocrinol. 24, 831-840.

27. Landgraf R. 1985 Plasma oxytocin concentrations in man after different routes of administration of synthetic oxytocin. Exp. Clin. Endocr. Diab. 85, 245-248.

28. Leake RD, Weitzman RE, Fisher DA. 1981 Oxytocin concentrations during the neonatal period. Neonatology 39, 127-131. 


\section{K.J. Robinson}

534 29. Leng G, Sabatier N. 2016 Measuring oxytocin and vasopressin: bioassays, immunoassays 535 and random numbers. J. Neuroendocrinol. 28, 1-13.

536 30. McCafferty DJ, Moss S, Bennett K, Pomeroy PP. 2005 Factors influencing the radiative

537 surface temperature of grey seal (Halichoerus grypus) pups during early and late

538 lactation. J. Comp. Physiol. B 175, 423-431.

539 31. Metcalfe NB, Monaghan P. 2001 Compensation for a bad start: grow now, pay later?

$540 \quad$ Trends Ecol. Evol. 16, 254-260.

541 32. Modahl C, Green LA, Fein D, Morris M, Waterhouse L, Feinstein C, Levin H. 1998

542 Plasma oxytocin levels in autistic children. Biol. Psychiat. 43, 270-277.

543 33. Nagasawa M, Okabe S, Mogi K, Kikusui T. 2012 Oxytocin and mutual communication in 544 mother-infant bonding. Front. Hum. Neurosci. 6, 98-107.

545 34. Nagasawa M, Mitsui S, En S, Ohtani N, Ohta M, Sakuma Y, Onaka T, Mogi K, Kikusui

546 T. 2015 Oxytocin-gaze positive loop and the coevolution of human-dog bonds. Science, $547 \quad 348,333-336$.

548 35. O'Connell LA, Matthews BJ, Hofmann HA. 2012 Isotocin regulates paternal care in a 549 monogamous cichlid fish. Horm. Behav. 61, 725-733.

550 36. Olszewski PK, Klockars A, Schiöth HB, Levine AS. 2010 Oxytocin as feeding inhibitor: 551 maintaining homeostasis in consummatory behavior. Pharmacol. Biochem. Be. 97, 47-54. 552 37. Pomeroy PP, Fedak MA, Rothery P, Anderson S. 1999 Consequences of maternal size for 553 reproductive expenditure and pupping success of grey seals at North Rona, Scotland. J. $554 \quad$ Anim. Ecol. 68, 235-253.

555 38. Quintana DS, Rokicki J, van der Meer D, Alnæs D, Kaufmann T, Córdova-Palomera A, 556 Dieset I, Andreassen OA, Westlye LT. 2019 Oxytocin pathway gene networks in the 557 human brain. Nat. Commun. 10, 668. 


\section{K.J. Robinson}

39. R Development Core Team. 2012. R: A language and environment for statistical computing. R Foundation for Statistics Computing, Vienna, Austria. Available from: http://www.R-project.org.

40. Rault JL, Ferrari J, Pluske JR, Dunshea FR. 2015 Neonatal oxytocin administration and supplemental milk ameliorate the weaning transition and alter hormonal expression in the gastrointestinal tract in pigs. Domest. Anim. Endocrin. 51, 19-26.

41. Redman P. 2002 The role of temporal, spatial and kin associations in grey seal breeding colonies. Doctoral Thesis. University of St Andrews.

42. Reilly JJ. 1991 Adaptations to prolonged fasting in free-living weaned gray seal pups. Am. J. Physiol-Reg. I 260, 267-272.

43. Rice D, Barone S. 2000 Critical periods of vulnerability for the developing nervous system: evidence from humans and animal models. Environ. Health Persp. 108, 511.

44. Rilling JK, Young LJ. 2014 The biology of mammalian parenting and its effect on offspring social development. Science 345, 771-776.

45. Robinson KJ (2014) The role of oxytocin in the maternal behaviour of the grey seal (Halichoerus grypus). Doctoral thesis, the University of St Andrews immunoassay (ELISA) plasma oxytocin in a novel mammal species reveals potential errors induced by sampling procedure. J. Neurosci. Meth. 226, 73-39.

47. Robinson KJ, Twiss SD, Hazon N, Pomeroy PP. 2015a Maternal oxytocin is linked to close mother-infant proximity in grey seals (Halichoerus grypus). PloS one 10, e0144577. 48. Robinson KJ, Twiss SD, Hazon N, Moss S, Lonergan M, Pomeroy PP. 2015b Conspecific recognition and aggression reduction to familiars in newly weaned, socially plastic mammals. Behav. Ecol. Sociobio. 69, 1383-1394. 


\section{K.J. Robinson}

49. Robinson KJ, Twiss SD, Hazon N, Moss S, Pomeroy PP. 2017 Positive social behaviours are induced and retained after oxytocin manipulations mimicking endogenous concentrations in a wild mammal. Proc. R. Soc. B 284, 20170554.

50. Ross HE, Young LJ. 2009 Oxytocin and the neural mechanisms regulating social cognition and affiliative behavior. Front. Neuroendocrin. 30, 534-547.

51. Samuni L, Preis A, Mundry R, Deschner T, Crockford C, Wittig RM. 2016 Oxytocin reactivity during intergroup conflict in wild chimpanzees. P. Natl. Acad. Sci. USA 114, 268-273.

52. Shields B, Wacogne I, Wright CM. 2012 Weight faltering and failure to thrive in infancy and early childhood. Brit. Med. J. 345, e5931.

53. Smout S, King R, Pomeroy P. 2011 Estimating demographic parameters for capturerecapture data in the presence of multiple mark types. Environ. Ecol. Stat. 18, 331-347. 2010 Hormonal mechanisms of cooperative behaviour. Philos. T. Roy. Soc. B. 365, 27372750.

55. Strathearn L, Fonagy P, Amico J, Montague PR. 2009 Adult attachment predicts maternal brain and oxytocin response to infant cues. Neuropsychopharmacol. 34, 2655-2666. Schneiderman N, Mendez AJ. 2011 Evaluation of enzyme immunoassay and radioimmunoassay methods for the measurement of plasma oxytocin. Psychosom. Med. $73,393$. oxytocin injections cause sustained weight gain and increased nociceptive thresholds in male and female rats. Pediatr. Res. 43, 344-348. 


\section{K.J. Robinson}

58. Valstad M, Alvares GA, Andreassen OA, Westlye LT, Quintana DS. 2017 The correlation between central and peripheral oxytocin concentrations: a systematic review and meta-analysis. Neurosci. Biobehav. R. 78, 117-124.

59. Wood S. 2006 Generalized Additive Models: An introduction with R. Chapman and Hall/CRC

\section{Figure Legends}

Figure 1. OT concentrations in mothers and pups. Mean basal plasma oxytocin $(\mathrm{pg} / \mathrm{ml})$ in grey seal mothers and their pups during early and late lactation with median, upper and lower quartiles, $1.5 x$ interquartile range and outliers shown. Significant differences at the $p<0.001$ level between groups are denoted by asterisks.

Figure 2. Mother - pup plasma oxytocin relationships. Prediction plot showing the GAMM output of the relationship between mother and pup plasma oxytocin concentration $(\mathrm{pg} / \mathrm{ml})$ on North Rona (solid line) and the Isle of May (dashed line).

Figure 3. Maternal presence as drivers of high infant OT. Mean basal plasma oxytocin (pg/ml) pups during early lactation, late lactation and post-weaning with median, upper and lower quartiles, $1.5 \mathrm{x}$ interquartile range and outliers shown. Significant differences at the $\mathrm{p}<0.001$ level between groups are denoted by asterisks. 


\section{K.J. Robinson}

629 Figure 4. OT concentrations and pup mass gain rate. The significant positive relationship

630 between pup plasma oxytocin concentrations $(\mathrm{pg} / \mathrm{ml})$ and the mass a pup gains per day while still

631 with its mother (kg/day) with the Pearson's correlation significance value.

632

633 Figure 5. Positive mother - infant OT loops and infant mass gain. Proposed double positive

634 feedback loop involving oxytocin (OT) release, mother-pup bonding and behaviour and mass

635 changes in grey seals.

636

637

638

639

640

641

642

643

644

645

646

647

648 


\section{K.J. Robinson}

649 Appendix Files for "High oxytocin infants gain more mass with no additional maternal energetic

650 costs in a natural system” by Kelly J. Robinson, Neil Hazon, Sean D. Twiss and Patrick P.

651 Pomeroy.

652

653 Appendix A. Methods

654

655 Milk Sample Analysis

656 The protocol supplied with the oxytocin ELISA was followed for analysing the two milk samples

657 with the following alterations;

658 1. In addition to the clarification protocol given with the ELISA, milk samples then underwent solid-phase extraction with the same protocol used to extract plasma samples (Robinson et al., 2014).

2. The two milk samples were run on the ELISA plate diluted to 1:2.

662

663 Statistical Analysis

664

665 All analyses were performed using the statistical package R 3.4.1 (R Development Core Team, 666 2012).

668 GAMM for investigating oxytocin concentrations detected in dependent pups

669 Biologically plausible explanatory variables used in this GAMM (Wood, 2006a) model was

670 plasma oxytocin concentration of the pup's mother, sample timing during the season (early or late

671 lactation), the pup's sex, the colony the pup was born on (NR or IoM) and the year of sampling

672 (2010 or 2011). The model was fitted using the multiple generalized cross validation library mgcv

673 (Wood, 2012). The identities of the mothers were fitted as a random effects smooth (Wood,

$6742006 \mathrm{~b}$ ) to control for pseudo-replication in the dataset from using some of the same individuals 


\section{K.J. Robinson}

675 over the two years of the study and to control for consistent individual differences in behaviour

676 (Twiss et al, 2012; Robinson et al., 2015a). The smoothing parameters were set by maximum

677 likelihood to reduce the risk of over fitting associated with other methods (Wood, 2011). The

678 model was fitted with a Gamma error distribution. Model selection was done by backwards

679 stepwise elimination through examination of $\mathrm{R}^{2}$ values, AIC values, QQ and residual plots to

680 identify the best model for the data. During the selection process, the 'year of sampling' variable

681 was discarded to improve the model's fit to the data and the 'plasma oxytocin concentration of

682 the mother', 'timing during season' (early/late), 'pup sex' and 'colony' variables were retained.

684 Final GAMM code for investigating oxytocin concentrations detected in dependent pups;

685 GammOutput $<$ - gam(PupOxytocin $\sim$ MotherOxytocin + EarlyLateLactation + PupSex +

$$
\text { Colony }+\mathrm{s}(\mathrm{ID}, \mathrm{bs}=" \mathrm{re} "), \text { family=Gamma(link="log"), method="ML", }
$$
data $=$ GreySealOxytocinData)

GAMMs for investigating mass gain in pups and mass loss in mothers

690 Biologically plausible explanatory variables used in these GAMM models (Wood, 2006a) were

691 plasma oxytocin concentration of the pup or mother (mean of early/late concentrations in pups for

692 pup model, early and late concentrations separately for mother model) and the pup's sex. The

693 models were fitted using the multiple generalized cross validation library mgcv (Wood, 2012).

694 The identities of the mothers were fitted as a random effects smooth (Wood, 2006b) for the same

695 reasons given above. The colony the mother-pup pair belonged to (NR or IoM) was also fitted as

696 a random effect smooth based on the results of the first GAMM model described above. The

697 smoothing parameters were set by maximum likelihood to reduce the risk of over fitting

698 associated with other methods (Wood, 2011). Models were fitted with a Gaussian error

699 distribution. Model selection was performed by backwards stepwise elimination through

700 examination of R2 values, AIC values, QQ and residual plots to identify the best model for the 


\section{K.J. Robinson}

701 data. When selecting variables for the model of pup mass gain rate, removing the 'pup sex'

702 variable improved the model's fit to the data. During the selection process for the models of

703 maternal mass loss, the 'pup sex' variable was removed to improve the model's fit to the data.

705 Final GAMM code for investigating mass gain in pups;

706 GammOutput $<$ - gam(PupMassGain $\sim$ PupOxytocinMean + s(ID, bs="re" $)+$ s(Colony, bs="re"), method="ML", data=GreySealOxytocinMassData)

709 Final GAMM code for investigating mass loss in mothers;

710 GammOutput3 <-gam(MotherMassLossTransformed $\sim$ MotherOxytocinEarlyLactation + MotherOxytocinLateLactation + s(ID, bs="re") + s(colony, bs="re"), 
K.J. Robinson

\section{Figure A.1}

728 Pup oxytocin concentrations in early and late lactation $(\mathrm{pg} / \mathrm{ml})$.

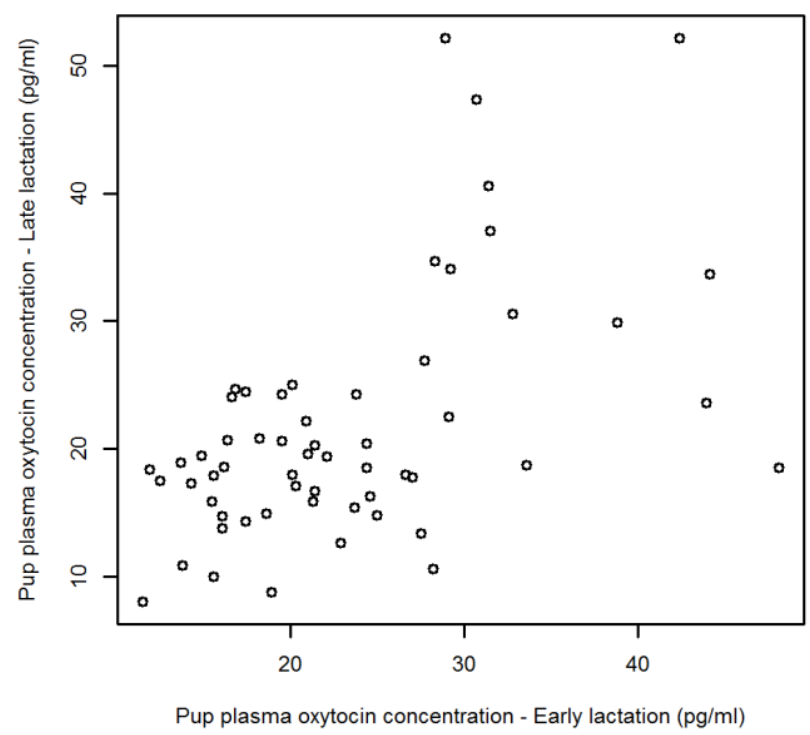

\section{$731 \quad$ Figure A.2}

732 Mother oxytocin concentrations in early and late lactation $(\mathrm{pg} / \mathrm{ml})$.

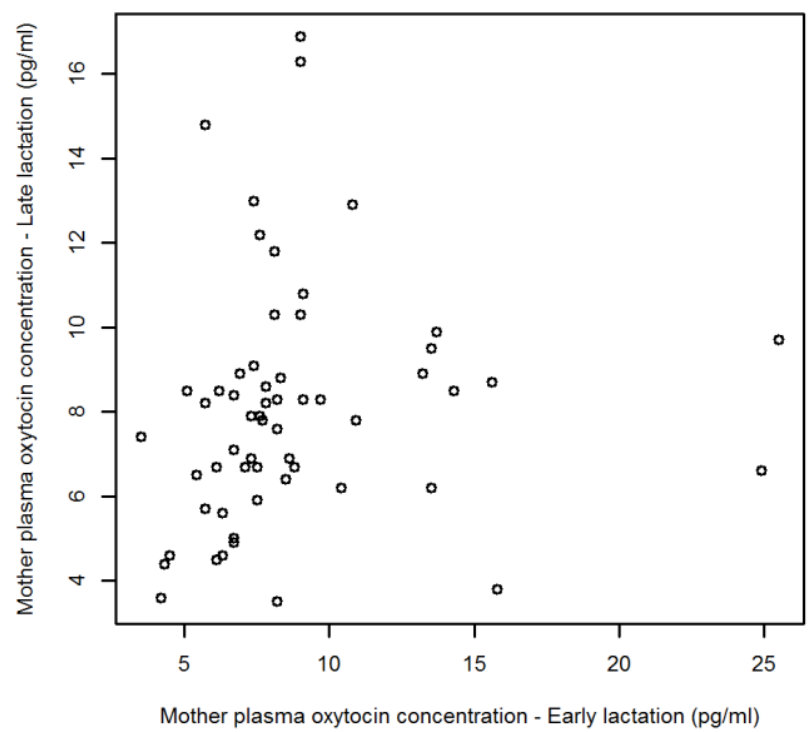




\section{K.J. Robinson}

736 1. R Development Core Team. 2012. R: A language and environment for statistical

737 computing. R Foundation for Statistics Computing, Vienna, Austria. Available from:

$738 \quad$ http://www.R-project.org.

739 2. Robinson KJ, Hazon N, Lonergan M, Pomeroy PP. 2014 Validation of an enzyme-linked

740 immunoassay (ELISA) plasma oxytocin in a novel mammal species reveals potential

741 errors induced by sampling procedure. J. Neurosci. Meth. 226, 73-39.

742 3. Robinson KJ, Twiss SD, Hazon N, Moss S, Lonergan M, Pomeroy PP. 2015 Conspecific

743 recognition and aggression reduction to familiars in newly weaned, socially plastic

744 mammals. Behav. Ecol. Sociobiol. 69, 1383-1394.

745 4. Twiss SD, Cairns C, Culloch RM, Richards SA, Pomeroy PP. 2012 Variation in female

746 grey seal (Halichoerus grypus) reproductive performance correlates to proactive-reactive

$747 \quad$ behavioural types. PLOS one 7, e49598.

748 5. Wood S. 2006a Generalized Additive Models: An introduction with R. Chapman and $749 \quad$ Hall/CRC

750 6. Wood S. 2006b Low-rank scale-invariant tensor product smooths for generalized additive 751 mixed models. Biometrics 62, 1025-1036.

752 7. Wood S. 2011 Fast stable restricted maximum likelihood and marginal likelihood 753 estimation of semiparametric generalized linear models. J. Roy. Stat. Soc. B. 73, 3-36.

754 8. Wood S. 2012. mgcv: Mixed GAM Computation Vehicle with GCV/AIC/REML 755 smoothness estimation. Available from: https://CRAN.R-project.org/package=mgcv 


\section{K.J. Robinson}

\section{Appendix B. Tables}

761

\section{Table B.1}

763 GAMM output for variables affecting pup oxytocin concentrations in plasma, their estimates,

764 standard errors and $\mathrm{p}$ values.

\begin{tabular}{|c|c|c|c|c|}
\hline Dependent variable & Explanatory variable & Estimate & $\begin{array}{l}\text { Standard } \\
\text { Error }\end{array}$ & P value \\
\hline $\begin{array}{l}\text { Pup oxytocin } \\
\text { concentration }(\mathrm{pg} / \mathrm{ml})\end{array}$ & $\begin{array}{r}\text { Maternal plasma oxytocin } \\
\text { concentration }(\mathrm{pg} / \mathrm{ml})\end{array}$ & 0.019 & 0.0083 & 0.02 \\
\hline & $\begin{array}{r}\text { Sample timing during the season } \\
\text { (early/late) }\end{array}$ & -0.052 & 0.053 & 0.33 \\
\hline & Pup sex (male/female) & 0.077 & 0.065 & 0.24 \\
\hline & $\begin{array}{r}\text { Colony (North Rona/Isle of } \\
\text { May) }\end{array}$ & 0.34 & 0.071 & $<0.001$ \\
\hline & $\begin{array}{r}\text { Smooth term for mother's } \\
\text { identity }\end{array}$ & $\mathrm{Na}$ & $\mathrm{Na}$ & 0.02 \\
\hline
\end{tabular}

Table B.2

767 GAMM output for variables affecting pup mass gain rate, their estimates, standard errors and $\mathrm{p}$

768 values.

\begin{tabular}{|l|r|r|r|r|}
\hline Dependent variable & Explanatory variable & Estimate & $\begin{array}{l}\text { Standard } \\
\text { Error }\end{array}$ & P value \\
\hline $\begin{array}{l}\text { Rate of mass gain in } \\
\text { pups (kg/day) }\end{array}$ & $\begin{array}{r}\text { Mean pup oxytocin } \\
\text { concentration (pg/ml) }\end{array}$ & 0.02 & 0.007 & $\mathbf{0 . 0 1 6}$ \\
\hline & $\begin{array}{r}\text { Smooth term for colony (North } \\
\text { Rona/Isle of May) }\end{array}$ & $\mathrm{Na}$ & $\mathrm{Na}$ & 0.07 \\
\hline & $\begin{array}{r}\text { Smooth term for mother's } \\
\text { identity }\end{array}$ & $\mathrm{Na}$ & $\mathrm{Na}$ & 0.06 \\
\hline
\end{tabular}




\section{K.J. Robinson}

Table B.3

776 GAMM output for variables affecting mother mass gain rate, their estimates, standard errors and

777 p values.

\begin{tabular}{|l|r|r|r|r|}
\hline Dependent variable & Explanatory variable & Estimate & $\begin{array}{l}\text { Standard } \\
\text { Error }\end{array}$ & P value \\
\hline $\begin{array}{l}\text { Rate of mass loss in } \\
\text { mothers (kg/day) } \\
\text { transformed by maternal } \\
\text { size close to parturition }\end{array}$ & $\begin{array}{r}\text { Maternal oxytocin } \\
\text { concentration during early } \\
\text { lactation }(\mathrm{pg} / \mathrm{ml})\end{array}$ & 0.00017 & 0.00012 & 0.17 \\
\hline & $\begin{array}{r}\text { Maternal oxytocin } \\
\text { concentration during late } \\
\text { lactation (pg/ml) }\end{array}$ & 0.00030 & 0.00018 & 0.11 \\
\hline & $\begin{array}{r}\text { Smooth term for colony } \\
\text { (North Rona/Isle of May) }\end{array}$ & $\mathrm{Na}$ & $\mathrm{Na}$ & 0.25 \\
\hline & $\begin{array}{r}\text { Smooth term for mother's } \\
\text { identity }\end{array}$ & $\mathrm{Na}$ & $\mathrm{Na}$ & 0.07 \\
\hline
\end{tabular}

778

779

780

781

782

783

784

785

786

787

788

789

790

791 


\section{K.J. Robinson}

794 When put into context with the volumes of milk a seal pup ingests daily, it is apparent that the OT

795 levels in seal milk are not high enough to impact on plasma concentrations. The mean volume of

796 milk a grey seal pup ingests is 3030ml/day (Iverson et al., 1993). Using the mean OT

797 concentration in grey seal milk detected in this study $(112.2 \mathrm{pg} / \mathrm{ml})$, a grey seal pup ingests

798 approximately 339966 pg of oxytocin per day, or $0.48 \%$ of the lowest buccal dose that has been

799 shown to have no effect on plasma OT levels (Table C.4). Furthermore, in seals this intake is split

800 into approximately five suckling bouts in a 24-hour period (Iverson et al., 1993). Therefore, on

801 average pups only consume $67993.2 p g$ of OT per suckling bout, or $0.01 \%$ of the buccal dose

802 which had no demonstrable effect on plasma OT levels (Table C.4). Pups would have to drink far

803 greater quantities of milk than they actually consume within a two-hour period to approach the

804 doses proven to significantly raise plasma OT concentrations. As this study had only two milk

805 samples to calculate ingested OT from, the high milk OT values from mice reported in Higashida

806 et al. (2010) can also be used to demonstrate that their levels would still not be high enough to

807 impact pup plasma levels. Mouse milk from Higashida et al. (2010) contained approximately

$8081,200 \mathrm{pg} / \mathrm{ml} \mathrm{OT}$, which would mean if a seal pup had a mother producing comparable levels of

809 OT in her milk, the pup would ingest 3,636,000pg of OT per day, or 5\% (1\% if splitting the

810 ingestion over five suckling bouts per day) of the lowest buccal dose that has been shown to have

811 no effect on plasma OT levels (Table C.4). Therefore, it is unlikely that ingested milk is the

812 source of the high plasma OT concentrations found in pups consistently throughout early and late

813 lactation. Other aspects of the mother's presence, potentially including scent, sounds and sight of

814 the mother, are more credible stimuli for release of the hormone within the pup. 


\section{K.J. Robinson}

815 Table C.4 Experimentally tested buccal doses of oxytocin for adult humans and their success

816 rates.

\begin{tabular}{|l|l|l|l|l|}
\hline $\begin{array}{l}\text { Buccal dose } \\
\text { given (units as } \\
\text { stated in source) }\end{array}$ & $\begin{array}{l}\text { Frequency } \\
\text { administered }\end{array}$ & $\begin{array}{l}\text { Total dose given } \\
\text { in picograms }\end{array}$ & Successful? & Reference \\
\hline $70 \mu \mathrm{g}$ & Once & $70,000,000 \mathrm{pg}$ & No & Landgarf, 1985 \\
\hline $200 \mathrm{IU}$ & $\begin{array}{l}\text { Every 20 } \\
\text { minutes for 2 } \\
\text { hours }\end{array}$ & $2,400,000,000 \mathrm{pg}$ & No & $\begin{array}{l}\text { Dawood et al., } \\
1980\end{array}$ \\
\hline $400 \mathrm{IU}$ & $\begin{array}{l}\text { Every 20 } \\
\text { minutes for 2 } \\
\text { hours }\end{array}$ & $4,800,000,000 \mathrm{pg}$ & $\begin{array}{l}\text { Yes (majority } \\
\text { elevated to 24 - } \\
50 \mathrm{pg} / \mathrm{ml})\end{array}$ & $\begin{array}{l}\text { Dawood et al., } \\
1980\end{array}$ \\
\hline
\end{tabular}

817

818 References

819 1. Dawood MY, Ylikorkala O, Fuchs F. 1980 Plasma oxytocin levels and disappearance rate 820 after buccal Pitocin. Am. J. Obstet. Gynecol. 138, 20-24.

821 2. Higashida H, Lopatina O, Yoshihara T, Pichugina YA, Soumarokov AA, Munesue T,

822 Minabe Y, Kikuchi M, Ono Y, Korshunova N, Salmina, AB. 2010 Oxytocin signal and 823 social behaviour: comparison among adult and infant oxytocin, oxytocin receptor and 824 CD38 gene knockout mice. J. Neuroendocrinol. 22, 373-379.

825 3. Iverson SJ, Bowen WD, Boness DJ, Oftedal OT. 1993 The effect of maternal size and 826 milk energy output on pup growth in grey seals (Halichoerus grypus). Physiol. Zool. 66, $827 \quad 61-88$

828 4. Landgraf R. 1985 Plasma oxytocin concentrations in man after different routes of

829 administration of synthetic oxytocin. Exp. Clin. Endocr. Diab. 85, 245-248.

830

831 Appendix D. Original data. For 'Pup post-wean OT (pg/ml) column, codes for individuals not 832 sampled are as follows: NA: not applicable, SCO: single capture only, NRC: not re-captured 


\begin{tabular}{|c|c|c|c|c|c|c|c|c|c|}
\hline $\begin{array}{l}\text { Mother } \\
\text { ID }\end{array}$ & $\begin{array}{l}\text { Pup OT } \\
\text { (pg/ml) }\end{array}$ & $\begin{array}{l}\text { Mother OT } \\
(\mathrm{pg} / \mathrm{ml})\end{array}$ & Colony & Year & $\begin{array}{l}\text { Early or late } \\
\text { lactation }\end{array}$ & $\begin{array}{l}\text { Pup } \\
\text { sex }\end{array}$ & $\begin{array}{l}\text { Pup mass gain } \\
\text { rate }(\mathrm{kg} / \mathrm{day})\end{array}$ & $\begin{array}{l}\text { Transformed mother mass loss } \\
\text { (mass specific rate, } \mathrm{kg} / \mathrm{day} \text { ) }\end{array}$ & $\begin{array}{l}\text { Pup post-wean } \\
\text { OT }(\mathrm{pg} / \mathrm{ml})\end{array}$ \\
\hline $\mathrm{R}$ & 15.1 & 9.5 & NR & 2010 & $E$ & $M$ & SCO & SCO & NRC \\
\hline$S$ & 27.7 & 7.4 & NR & 2010 & E & $M$ & 2.18 & 0.021538462 & 6.7 \\
\hline$S$ & 26.9 & 9.1 & NR & 2010 & L & $M$ & NA & NA & NA \\
\hline $\mathrm{T}$ & 11.9 & 6.7 & NR & 2010 & E & $\mathrm{F}$ & 2.254545455 & 0.0120012 & NRC \\
\hline $\mathrm{T}$ & 18.4 & 8.4 & NR & 2010 & L & $\mathrm{F}$ & NA & NA & NRC \\
\hline$U$ & 16.4 & 8.3 & NR & 2010 & E & $\mathrm{F}$ & 2.795833333 & 0.022610405 & NRC \\
\hline U & 20.7 & 8.8 & NR & 2010 & L & $\mathrm{F}$ & NA & NA & NRC \\
\hline V & 33.6 & 7.5 & NR & 2010 & E & $M$ & 2.177777778 & 0.017364248 & NRC \\
\hline V & 18.7 & 6.7 & NR & 2010 & L & $M$ & NA & NA & NRC \\
\hline W & 21 & 15.8 & NR & 2010 & E & $\mathrm{F}$ & 1.84 & 0.026219512 & NRC \\
\hline W & 19.6 & 3.8 & NR & 2010 & L & $\mathrm{F}$ & NA & NA & NRC \\
\hline$A$ & 28.2 & 25.5 & NR & 2011 & E & $M$ & 2.89 & 0.025224327 & 8.2 \\
\hline$A$ & 10.6 & 9.7 & NR & 2011 & L & $M$ & NA & NA & NA \\
\hline $\mathrm{H}$ & 21.4 & 24.9 & NR & 2011 & E & $M$ & 2.3 & 0.022289258 & 12.6 \\
\hline $\mathrm{H}$ & 20.3 & 6.6 & NR & 2011 & L & $\mathrm{M}$ & NA & NA & NA \\
\hline $\mathrm{J}$ & 30.7 & 7.6 & NR & 2011 & E & $\mathrm{F}$ & 2.6 & 0.026589595 & 10.8 \\
\hline $\mathrm{J}$ & 47.4 & 12.2 & NR & 2011 & L & $\mathrm{F}$ & NA & NA & NA \\
\hline$x$ & 31.5 & 8.2 & NR & 2011 & E & $\mathrm{F}$ & 2.255 & 0.022246456 & NRC \\
\hline$x$ & 37.1 & 8.3 & NR & 2011 & L & $\mathrm{F}$ & NA & NA & NRC \\
\hline Y & 36.2 & 4.3 & NR & 2011 & E & $M$ & sco & sco & NRC \\
\hline L & 28.3 & 6.9 & NR & 2011 & $E$ & $\mathrm{~F}$ & 2.354545455 & 0.024467649 & 15.1 \\
\hline $\mathrm{L}$ & 34.7 & 8.9 & NR & 2011 & L & $\mathrm{F}$ & NA & NA & NA \\
\hline$M$ & 29.2 & 13.2 & NR & 2011 & E & $\mathrm{F}$ & 1.7 & 0.018356589 & 14.1 \\
\hline$M$ & 34.1 & 8.9 & NR & 2011 & L & $\mathrm{F}$ & NA & NA & NA \\
\hline$N$ & 43.9 & 15.6 & NR & 2011 & E & $M$ & 2.325 & 0.022449336 & NRC \\
\hline $\mathrm{N}$ & 23.6 & 8.7 & NR & 2011 & L & $\mathrm{M}$ & NA & NA & NRC \\
\hline$P$ & 44.1 & 13.7 & NR & 2011 & E & $M$ & 2.36 & 0.02452381 & 20.5 \\
\hline$P$ & 33.7 & 9.9 & NR & 2011 & L & $M$ & NA & NA & NA \\
\hline $\mathrm{O}$ & 22.1 & 3.3 & NR & 2011 & E & $\mathrm{F}$ & sco & sco & NRC \\
\hline$U$ & 31.4 & 7.4 & NR & 2011 & E & $M$ & 2.745454545 & 0.01338091 & NRC \\
\hline$U$ & 40.6 & 13 & NR & 2011 & L & $M$ & NA & NA & NRC \\
\hline
\end{tabular}




\begin{tabular}{|c|c|c|c|c|c|c|c|c|c|c|c|}
\hline $\begin{array}{l}\text { Mother } \\
\text { ID }\end{array}$ & $\begin{array}{l}\text { Pup OT } \\
\text { (pg/ml) }\end{array}$ & $\begin{array}{l}\text { Mother OT } \\
(\mathrm{pg} / \mathrm{ml})\end{array}$ & Colony & Year & $\begin{array}{l}\text { Early or late } \\
\text { lactation }\end{array}$ & $\begin{array}{l}\text { Pup } \\
\text { sex }\end{array}$ & $\begin{array}{l}\text { Pup mass gain } \\
\text { rate }(\mathrm{kg} / \mathrm{day})\end{array}$ & \multicolumn{2}{|c|}{$\begin{array}{l}\text { Transformed mother mass loss } \\
\text { (mass specific rate, } \mathrm{kg} / \text { day) }\end{array}$} & \multicolumn{2}{|c|}{$\begin{array}{l}\text { Pup post-wean } \\
\text { OT }(\mathrm{pg} / \mathrm{ml})\end{array}$} \\
\hline W & 15.6 & 6.3 & NR & 2011 & E & $M$ & 1.73 & & 0.026209677 & & 13.9 \\
\hline W & 17.9 & 5.6 & NR & 2011 & $\mathrm{~L}$ & $M$ & NA & NA & & NA & \\
\hline $\mathrm{T}$ & 27.5 & 9.7 & NR & 2011 & E & $\mathrm{F}$ & 2.3 & & 0.02213762 & NRC & \\
\hline $\mathrm{T}$ & 13.4 & 8.3 & NR & 2011 & L & $\mathrm{F}$ & NA & NA & & NRC & \\
\hline Z & 22.1 & 9 & IOM & 2010 & E & $M$ & 2.066666667 & & 0.021982414 & & 38.9 \\
\hline $\bar{Z}$ & 19.4 & 10.3 & IOM & 2010 & L & $\mathrm{M}$ & NA & NA & & NA & \\
\hline AA & 23.8 & 5.7 & IOM & 2010 & $\mathrm{E}$ & $\mathrm{F}$ & 2.222222222 & & 0.021668472 & & 9.6 \\
\hline AA & 24.3 & 5.7 & IOM & 2010 & L & $\mathrm{F}$ & NA & NA & & NA & \\
\hline BB & 13.7 & 8.1 & IOM & 2010 & $\mathrm{E}$ & $M$ & 1.866666667 & & 0.020150419 & & 25.2 \\
\hline BB & 18.9 & 10.3 & IOM & 2010 & L & $\mathrm{M}$ & NA & NA & & NA & \\
\hline $\mathrm{CC}$ & 14.9 & 6.7 & IOM & 2010 & $\mathrm{E}$ & $\mathrm{M}$ & 2.25 & & 0.020120898 & & 11.4 \\
\hline $\mathrm{CC}$ & 19.5 & 4.9 & IOM & 2010 & $\bar{L}$ & $\mathrm{M}$ & NA & NA & & NA & \\
\hline DD & 16.6 & 13.5 & IOM & 2010 & E & $\mathrm{F}$ & 1.671428571 & & 0.020493912 & NRC & \\
\hline DD & 24.1 & 6.2 & IOM & 2010 & L & $\mathrm{F}$ & NA & NA & & NRC & \\
\hline EE & 27 & 7.7 & IOM & 2010 & $\mathrm{E}$ & $\mathrm{M}$ & 2.314285714 & & 0.022569164 & & 24.5 \\
\hline EE & 17.8 & 7.8 & IOM & 2010 & $\mathrm{~L}$ & $\mathrm{M}$ & NA & NA & & NA & \\
\hline $\mathrm{FF}$ & 26.6 & 13.5 & IOM & 2010 & E & $\mathrm{M}$ & 1.616666667 & & 0.023644388 & & 11.7 \\
\hline $\mathrm{FF}$ & 18 & 9.5 & IOM & 2010 & L & $\mathrm{M}$ & NA & NA & & NA & \\
\hline GG & 28.9 & 10.4 & IOM & 2010 & E & $M$ & 1.872727273 & & 0.025245782 & & 12.9 \\
\hline GG & 52.2 & 6.2 & IOM & 2010 & L & $M$ & NA & NA & & NA & \\
\hline $\mathrm{HH}$ & 24.6 & 8.2 & IOM & 2010 & $\mathrm{E}$ & $\mathrm{M}$ & 1.969230769 & & 0.02572482 & & 18.3 \\
\hline $\mathrm{HH}$ & 16.3 & 7.6 & IOM & 2010 & $\bar{L}$ & $\mathrm{M}$ & NA & NA & & NA & \\
\hline II & 21.3 & 6.1 & IOM & 2010 & $\mathrm{E}$ & $\mathrm{F}$ & 2.125 & & 0.023020258 & & 14.3 \\
\hline II & 15.9 & 6.7 & IOM & 2010 & L & $\mathrm{F}$ & NA & NA & & NA & \\
\hline JJ & 18.2 & 9.1 & IOM & 2010 & $\mathrm{E}$ & $\mathrm{F}$ & 2.111111111 & & 0.027543789 & & 13 \\
\hline JJ & 20.8 & 10.8 & IOM & 2010 & L & $\mathrm{F}$ & NA & NA & & NA & \\
\hline KK & 24.4 & 8.8 & IOM & 2010 & $\mathrm{E}$ & $M$ & 2.4 & & 0.029495472 & & 13.5 \\
\hline KK & 18.5 & 6.7 & IOM & 2010 & L & $\mathrm{M}$ & NA & NA & & NA & \\
\hline LL & 18.9 & 7.3 & IOM & 2010 & $\mathrm{E}$ & $\mathrm{F}$ & 2.181818182 & & 0.027156041 & & 20.9 \\
\hline LL & 8.8 & 7.9 & IOM & 2010 & L & $\mathrm{F}$ & NA & NA & & NA & \\
\hline MM & 12.5 & 5.7 & IOM & 2010 & $\mathrm{E}$ & $\mathrm{F}$ & 1.66 & & 0.017397078 & & 11 \\
\hline
\end{tabular}




\begin{tabular}{|c|c|c|c|c|c|c|c|c|c|}
\hline $\begin{array}{l}\text { Mother } \\
\text { ID }\end{array}$ & $\begin{array}{l}\text { Pup OT } \\
\text { (pg/ml) }\end{array}$ & $\begin{array}{l}\text { Mother OT } \\
(\mathrm{pg} / \mathrm{ml})\end{array}$ & Colony & Year & $\begin{array}{l}\text { Early or late } \\
\text { lactation }\end{array}$ & $\begin{array}{l}\text { Pup } \\
\text { sex }\end{array}$ & $\begin{array}{l}\text { Pup mass gain } \\
\text { rate }(\mathrm{kg} / \text { day })\end{array}$ & $\begin{array}{l}\text { Transformed mother mass loss } \\
\text { (mass specific rate, } \mathrm{kg} / \mathrm{day} \text { ) }\end{array}$ & $\begin{array}{l}\text { Pup post-wean } \\
\text { OT (pg/ml) }\end{array}$ \\
\hline MM & 17.5 & 8.2 & IOM & 2010 & L & $\mathrm{F}$ & NA & NA & NA \\
\hline NN & 13.8 & 9.1 & IOM & 2010 & E & $M$ & 0.8 & 0.016148207 & NRC \\
\hline NN & 10.9 & 8.3 & IOM & 2010 & L & $M$ & NA & NA & NRC \\
\hline EE & 23.7 & 7.8 & IOM & 2011 & $\mathrm{E}$ & $\mathrm{F}$ & 1.842857143 & 0.02506535 & 10. \\
\hline EE & 15.4 & 8.2 & IOM & 2011 & $\mathrm{~L}$ & $\mathrm{~F}$ & NA & NA & NA \\
\hline OO & 15.6 & 3.5 & IOM & 2011 & $\mathrm{E}$ & $\mathrm{M}$ & 1.1 & 0.01633663 & 10. \\
\hline OO & 10 & 7.4 & IOM & 2011 & $\mathrm{~L}$ & $M$ & NA & NA & NA \\
\hline $\mathrm{FF}$ & 18.6 & 6.2 & IOM & 2011 & E & $M$ & 1.533333333 & 0.02279305 & 10. \\
\hline $\mathrm{FF}$ & 14.9 & 8.5 & IOM & 2011 & L & $\mathrm{M}$ & NA & NA & NA \\
\hline II & 15.5 & 5.4 & IOM & 2011 & E & $\mathrm{F}$ & 2.14 & 0.02450867 & 11. \\
\hline II & 15.9 & 6.5 & IOM & 2011 & L & $\mathrm{F}$ & NA & NA & NA \\
\hline $\mathrm{CC}$ & 11.5 & 4.3 & IOM & 2011 & E & $\mathrm{F}$ & 1.86 & 0.020927602 & NRC \\
\hline $\mathrm{CC}$ & 8 & 4.4 & IOM & 2011 & L & $\mathrm{F}$ & NA & NA & NRC \\
\hline $\mathrm{HH}$ & 25 & 6.7 & IOM & 2011 & E & $M$ & 1.166666667 & $0.02013422 \varepsilon$ & 7. \\
\hline $\mathrm{HH}$ & 14.8 & 5 & IOM & 2011 & L & $M$ & NA & NA & NA \\
\hline PP & 21.4 & 9 & IOM & 2011 & E & $\mathrm{F}$ & 1.371428571 & 0.02571896 & 10. \\
\hline PP & 16.7 & 16.9 & IOM & 2011 & L & $\mathrm{F}$ & NA & NA & NA \\
\hline KK & 20.3 & 8.6 & IOM & 2011 & E & $M$ & 1.742857143 & 0.028613507 & 12. \\
\hline KK & 17.1 & 6.9 & IOM & 2011 & $\mathrm{~L}$ & $M$ & NA & NA & NA \\
\hline QQ & 17.4 & 7.6 & IOM & 2011 & E & $M$ & 1.371428571 & 0.02291105 & 7. \\
\hline QQ & 14.3 & 7.9 & IOM & 2011 & $\mathrm{~L}$ & $M$ & NA & NA & NA \\
\hline JJ & 20.1 & 6.7 & IOM & 2011 & E & $\mathrm{F}$ & 2.2 & 0.02575695 & 6. \\
\hline JJ & 18 & 7.1 & IOM & 2011 & L & $\mathrm{F}$ & NA & NA & NA \\
\hline $\mathrm{RR}$ & 16.2 & 8.1 & IOM & 2011 & E & $M$ & 2.228571429 & 0.03081943 & 7. \\
\hline $\mathrm{RR}$ & 18.6 & 11.8 & IOM & 2011 & L & $M$ & NA & NA & NA \\
\hline GG & 22.9 & 7.1 & IOM & 2011 & E & $\mathrm{F}$ & 1.276923077 & 0.017932987 & 1 \\
\hline GG & 12.6 & 6.7 & IOM & 2011 & L & $\mathrm{F}$ & NA & NA & NA \\
\hline SS & 20.9 & 5.1 & IOM & 2011 & E & $\mathrm{F}$ & 1.553846154 & $0.02124946 s$ & 7. \\
\hline SS & 22.2 & 8.5 & IOM & 2011 & L & $\mathrm{F}$ & NA & NA & NA \\
\hline TT & 16.1 & 5.7 & IOM & 2011 & E & $\mathrm{F}$ & 1.836363636 & 0.026677353 & 4. \\
\hline TT & 13.8 & 14.8 & IOM & 2011 & $\mathrm{~L}$ & $\mathrm{~F}$ & NA & NA & NA \\
\hline LL & 16.1 & 10.8 & IOM & 2011 & $\mathrm{E}$ & $\mathrm{F}$ & 1.709090909 & 0.02157764 & 8. \\
\hline
\end{tabular}

